\title{
How the entire scientific community can confront gender bias in the workplace
}

\author{
Evidence overwhelmingly shows structural barriers to women in science, technology, engineering and mathematics \\ fields, and suggests that the onus cannot be on women alone to confront the gender bias in our community. \\ Here, I share my experience as a scientist and a woman who has collected data during more than ten years of \\ scientific training about how best to navigate the academic maze of biases and barriers.
}

\section{Kathleen E. Grogan}

ncreased gender and racial diversity benefits scientific progress through increased innovation ${ }^{1}$; however, few would argue we have reached optimal diversity along gender or racial lines. Thus, we should be using data to understand the barriers that have prevented attainment of this goal, as well as the potential solutions. Recently, a Nature feature offered advice from female scientists on how to confront the barriers we face ${ }^{2}$. Yet the assembled data suggest that it is impossible for the marginalized to solve these problems themselves. Women face biases and barriers at all turns within the scientific community, from publishing, funding and hiring, to promotion to more senior positions. As scientists, we are trained to objectively collect and evaluate the data available and carefully interpret them to reach empirically based conclusions. This same data-driven approach that guides our research should be applied to maximize the innovation and productivity of our scientific and academic community. What data we have are stark (Fig. 1).

\section{Less funding}

Women submit significantly fewer grants than men to the National Institutes of Health (NIH; $30.7 \%$ of applications versus $69.1 \%$, respectively) and National Science Foundation $(24.2 \% \text { versus } 75.8 \%)^{3,4}$. Once submitted, women are equally successful in obtaining funding compared with their male colleagues $^{3-5}$ (but see refs ${ }^{6-8}$ ). Despite the equal chance of success, however, women generally hold fewer simultaneous NIH grants and, as a result, have $\sim$ US $\$ 30,000$ less funding per year. Women also submit fewer renewal grants and are less likely to have these NIH renewal grants succeed ${ }^{3,8}$. Applicant race plays a crucial role as well - after controlling for education, training and publications, African-American NIH applicants are $10 \%$ less likely to be awarded a grant than white investigators?

\section{Under-representation in publishing}

Out of 115 science, technology, engineering and mathematics (STEM) fields identified by the sociology of science website http://eigenfactor.org, only 28 have reached $50 \%$ female authors overall. In biology and molecular biology, with overall representation of 37-38\% female authorship, these trends are driven by near gender parity in the first author

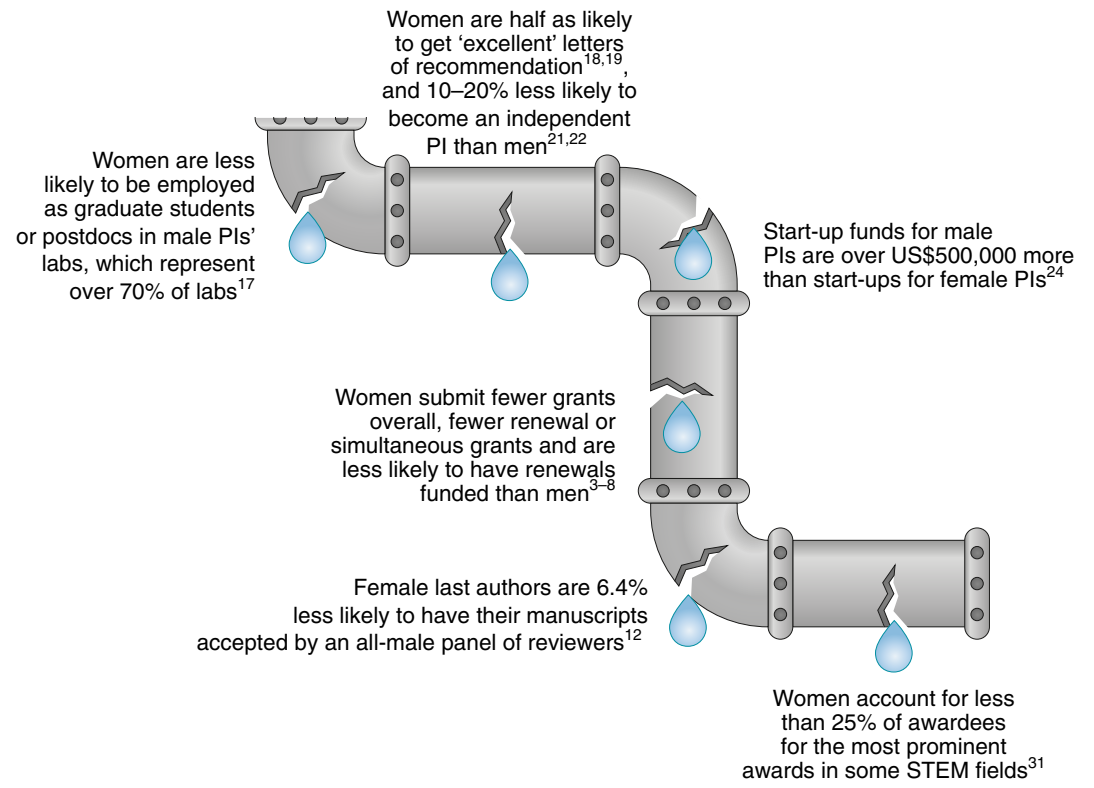

How can the entire STEM community address this gender bias problem?

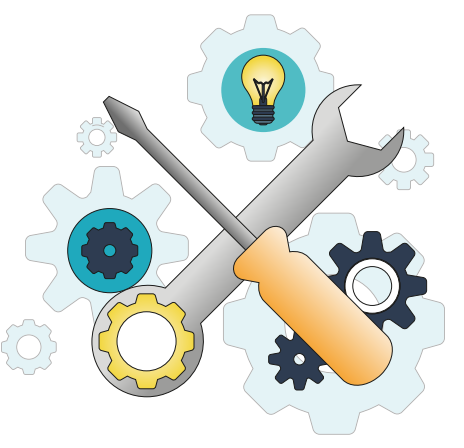

- Collect and publish data on gender representation in all areas of STEM visibility and success

- Set clear and specific goals and guidelines for gender and minority representation in your area of STEM

- Identify and offer effective training in unconscious bias and effective hiring and retention strategies

Fig. 1 | The leaky pipeline of women in STEM. The 'leaky pipeline' often depicts women passively leaking out of STEM careers with no discussion of why those leaks occur, but, in fact, the cracks and gaps caused by the biases and barriers are a major cause of the leak of women and minorities out of the STEM pipeline. PI, principal investigator. Credit: Gvais/Shutterstock (pipes and water), 32 pixels/Shutterstock (spanner and wrench). 


Table 1/ Additional resources on gender and racial bias
\begin{tabular}{ll} 
Website & Description \\
\hline http://www.eigenfactor.org/gender/ & Explore the gender of authors by authorship position in your field \\
http://www.raiseproject.org/ & Explore the gender representation of award recipients in various STEM organizations \\
http://benschmidt.org/profGender/ & In-depth visualization of how gender affects word choice in student evaluations \\
https://www.tomforth.co.uk/genderbias/ & Calculate the gender bias of your choice in letters of recommendation \\
https://diversity.nih.gov/ & Resources and research from the NIH Scientific Workforce Diversity Office \\
https://www.stemwomen.net/ & Resources on gender inequality and potential solutions \\
http://diversityinacademia.strikingly.com/ & Resources on racial inequality and potential solutions \\
https://nationalseedproject.org/ & $\begin{array}{l}\text { Peer-led professional development organization that provides training on engaging in conversations } \\
\text { about diversity and equity }\end{array}$ \\
http://blogs.Ise.ac.uk/ & Annotated bibliography of studies on gender bias in academia \\
impactofsocialsciences/2016/03/08/gender-bias- & \\
in-academe-an-annotated-bibliography/ & \\
https://fairplaygame.org/ & Online role-playing, true to life simulation of the complex social world for a minority graduate student \\
& in academia
\end{tabular}

position (43-45\% female authors); however, women represent only $27-28 \%$ of last authors ${ }^{10,11}$. At the current rate of increase of $0.5 \%$ in female authors per year, we will not reach gender parity in last author position for at least 50 years in biology and molecular biology ${ }^{10}$. Although manuscripts with female first authors are equally likely to be accepted as those with male first authors, papers with a male last or corresponding author are $3.0 \%$ and $3.7 \%$ more likely to be accepted than those with a female last or corresponding author, respectively ${ }^{12}$. Moreover, for high-impact journals, the likelihood a woman will be published as the first, last or corresponding author decreases significantly as the impact factor of the journal increases ${ }^{11}$.

Peer reviewer gender interacts with author gender to influence the probability of acceptance - mixed gender or all-female review panels equally accept manuscripts regardless of gender of the first, last or corresponding author. All-male review panels, however, accept significantly more manuscripts from papers with male last authors (56.8\% acceptance) than female last authors (50.4\%) or male corresponding authors (56.5\%) than female corresponding authors (51.4\%), although the gender of the first author does not influence the acceptance rate of an all-male review panel ${ }^{12}$. These data are striking because women are significantly under-represented on journal editorial boards and as journal reviewers ${ }^{12,13}$. At eLife, for example, $24.1 \%$ of editors and $20.7 \%$ of peer reviewers are women ${ }^{12}$. Once published, manuscripts in high-impact journals with men in key author positions are more frequently cited (38.9 citations per paper) than papers with women in key author positions in those same journals (35.2 citations per paper) ${ }^{11}$.

\section{Biases in recommendations and hiring}

Women have achieved parity with or even surpassed the number of men who graduate with bachelor's degrees in many scientific fields ${ }^{14}$; however, gender bias acts throughout the hiring, promotion and tenure process. Male candidates for a laboratory manager position are rated as significantly more competent and hirable than an identical female candidate and offered a US $\$ 4,000$ higher starting salary ${ }^{15}$. Importantly, faculty gender does not influence these results, meaning that unconscious gender bias is pervasive and not limited to a particular gender ${ }^{15}$. Faculty, regardless of gender, race or discipline, are more likely to respond to requests from white male prospective graduate students than from any other category of gender or race, particularly in higher-paying disciplines and at private institutions ${ }^{16}$.

In terms of gender distribution of lab personnel, male faculty employ $11 \%$ fewer female graduate students and $22 \%$ fewer female postdoctoral researchers compared to female faculty, and this trend intensifies in the labs of 'elite' male faculty (for example, those funded by the Howard Hughes Medical Institute or National Academy of Science members), but not in the labs of 'elite' female faculty ${ }^{17}$. Even letters of recommendation exhibit gender bias female candidates are half as likely as male candidates to receive an excellent letter or to have 'standout' adjectives like 'excellent', 'outstanding' or 'extraordinary' used in their letter, regardless of the gender of the letter writer ${ }^{18,19}$. After graduation, although women obtain over $50 \%$ of biology PhDs, they are vastly under-represented at the faculty level ${ }^{17,20}$. Across disciplines, women become primary investigators at a $10-20 \%$ lower rate than $\mathrm{men}^{21,22}$. Even in disciplines like anthropology, in which male and female faculty are hired at rates proportional to the gendered $\mathrm{PhD}$ graduation rates, women are significantly more likely to become faculty in non-PhD granting institutions whereas men are more likely to become faculty at $\mathrm{PhD}$ granting institutions ${ }^{23}$. Once hired, male $\mathrm{PhDs}$ report an average of nearly US\$600,000 more start-up funds than do female PhDs (US\$936,000 versus US $\$ 348,000)^{24}$.

\section{Less recognition and visibility}

Once hired, women and men are equally likely to become tenured and then promoted to full professor ${ }^{25}$ (but see refs ${ }^{26,27}$ ). Promotion depends on explicit criteria like publication and funding rates as well as other, subtler measures such as visibility and reputation. Women are less likely to be colloquium speakers at prestigious universities than men, regardless of the pool of available speakers, although the presence of women as colloquium chairs increases the likelihood of a women speaker ${ }^{28}$. Similarly, the proportion of female speakers at conferences in evolutionary biology is positively correlated with the proportion of female symposia organizers and the proportion of female speakers increases when gender is explicitly taken into account by symposia organizers ${ }^{29}$. The past two decades of biological anthropology conferences reflect similar findings: women give $65 \%$ of submitted talks or posters and comprise $64 \%$ and $58 \%$ of speakers in symposia planned by women-only or mixed-gender organizers, respectively, yet give only $29 \%$ of talks in male-only organized symposia ${ }^{30}$.

Women are significantly less likely to receive professional awards than men 
relative to their representation in the award pool $^{31}$. In anthropology, ecology, evolution and genetics specifically, women account for more than $50 \%$ of early career awardees for students and postdoctoral fellows; however, less than $25 \%$ of the mostprominent awards in these fields have been awarded to women. The Raise Project and data pulled from the American Association of Physical Anthropologists website (http://physanth.org) reveal that, since 2001, two women (11.7\%) have been awarded the Eminent Ecologist award from the Ecological Society of America, five women (29.4\%) have received the Society for the Study of Evolution's Dobzhansky Prize, three women (17.6\%) have won the Thomas Hunt Morgan Medal from the Genetics Society of America and two women (11.7\%) have received the Darwin Lifetime Achievement award from the American Association of Physical Anthropologists. Infamously, of the 601 people who have won Nobel prizes in the sciences from 1901 to 2018, only 21 (3.5\%) have been women, although for the first time this year, the Nobel committee asked nominators to include gender in their considerations ${ }^{32}$.

Gender bias appears even in small, seemingly inconsequential patterns of visibility - women ask fewer questions in seminars, especially when the first question is asked by a man, and women are featured in fewer advertisements in Science (8\%) and Nature (18\%) than are $\operatorname{men}^{33,34}$. Another component of faculty promotion is teaching evaluations, where women are rated significantly lower than men, regardless of the gender of the student evaluator ${ }^{35}$. Women even experience a collaboration disadvantage, as men are $15 \%$ more likely to share data when the request comes from another $\operatorname{man}^{36}$.

\section{Water can't fix the leaks in the pipeline}

The data here are focused on binary gender, the United States, and the fields of anthropology, ecology and evolution for reasons of availability, as well as my own experiences and focus as a woman and a US-based researcher. Yet women are not the only researchers who face barriers and biases in STEM, and the limited data we have suggest that problems are seriously magnified for all under-represented minority groups, especially for people whose identity is intersectional, for example, women and LGBTQ individuals of colour, people of colour with disabilities and so on. Calls for the marginalized to confront issues of diversity ${ }^{2}$ fail to recognize that we have limited power: for example, as a woman and a postdoc, my powers are limited to strategies such as combating my unconscious bias and highlighting how we can all work to address structural gender bias. I am not in a position of power, so I cannot make hiring or funding decisions, and I am not in the majority gender, so my voice is less heeded in the call to combat structural bias. We need the entire STEM community to actively lean into solving this gender bias problem, instead of asking only $30 \%$ of the community, the female part, to solve it among themselves ${ }^{2,37}$.

\section{What we can do}

To solve these problems, we need to think like scientists: that is, begin with the data and interrogate them. Studies suggest male STEM faculty evaluate research demonstrating gender bias as significantly lower in quality than female STEM faculty $\mathrm{do}^{38}$. This phenomenon is particularly problematic because increasing and retaining diversity of under-represented people in STEM necessarily requires acknowledgement of the data documenting the existence of bias before solutions can be found ${ }^{38}$. Thus, we need to assemble more current and historical data within our departments, journals, societies, conferences or funding agencies on gender representation within our organizations and our success rates, be they graduation, publication or funding rates (see Table 1 for a list of resources). We need to publish these data to confirm our commitments to diversity and to hold ourselves accountable. We must ask departments with better gender and racial representation in their student and faculty population what their strategies are for recruitment and retention ${ }^{39}$. We should identify potential unconscious bias training opportunities with evidence of effectiveness and mandate them for our departments before graduate or faculty recruitment as well as offering them at society meetings. We must ask if the criteria used for hiring, promotion and society awards are biased by gender or race or if women and other under-represented minority groups are being asked to do more non-promotable tasks and service work than are white men ${ }^{40-42}$. We can set clear, specific goals with targets and timelines for five and ten years in the future ${ }^{39}$.

On a smaller, individual scale, we can each recommend more female or minority reviewers for our manuscripts and quantify the gender bias in our own manuscript references for first and last author position. We can sign up for, use and create lists that curate women and under-represented minorities in our fields, like DiversifyEEB, FolksInGCB and DiversifyChemistry, to suggest reviewers or to nominate individuals for society prizes. Crucially, we must be aware of our own potential biases and work to address them in all areas of our work as scientists.

As one of the first cohorts of job candidates, hiring committees, grant and manuscript reviewers, journal editors and university and grant agencies administrations to be empowered by the data, we must ask ourselves, how will we make use of these data? I am working to create an inclusive atmosphere for those around me, calling attention to the data here and via social media, while striving for a tenure-track job where I can do more. What can you do right now and what will you be able to do in the future?

\section{Kathleen E. Grogan}

Departments of Anthropology and Biology,

Pennsylvania State University, State College, PA, USA.

e-mail:kathleen.e.grogan@gmail.com

Published online: 26 November 2018

https://doi.org/10.1038/s41559-018-0747-4

\section{References}

1. Nielsen, M. W. et al. Proc. Natl Acad. Sci. USA 114, 1740-1742 (2017)

2. Powell, K. Nature 561, 421-423 (2018).

3. Hechtman, L. A. et al. Proc. Natl Acad. Sci. USA 115, 7943-7948 (2018)

4. Report to the National Science Board on the National Science Foundation's Merit Review Process Fiscal Year 2016 (National Science Foundation, 2017).

5. Marsh, H. W., Bornmann, L., Mutz, R., Daniel, H.-D. \& O’Mara, A. Rev. Educ. Res. 79, 1290-1326 (2009).

6. Witteman, H. O., Hendricks, M., Straus, S. \& Tannenbaum, C. Preprint at https://doi.org/10.1101/232868 (2018)

7. van der Lee, R. \& Ellemers, N. Proc. Natl Acad. Sci. USA 112, 12349-12353 (2015)

8. Kaatz, A. et al. Acad. Med. 91, 1080-1088 (2016).

9. Ginther, D. K. et al. Science 333, 1015-1019 (2011).

10. Holman, L., Stuart-Fox, D. \& Hauser, C. E. PLoS Biol. 16, 1-20 (2018).

11. Bendels, M. H. K., Müller, R., Brueggmann, D. \& Groneberg, D. A. PLoS ONE 13, e0189136 (2018).

12. Murray, D. et al. Preprint at https://doi.org/10.1101/400515 (2018).

13. Fox, C. W., Burns, C. S. \& Meyer, J. A. Funct. Ecol. 30, 140-153 (2016).

14. Science and Engineering Indicators 2014 (National Science Foundation, 2014)

15. Moss-Racusin, C. A., Dovidio, J. F., Brescoll, V. L., Graham, M. J. \& Handelsman, J. Proc. Natl Acad. Sci. USA 109, 16474-16479 (2012).

16. Milkman, K. L., Akinola, M. \& Chugh, D. J. Appl. Psychol. 100 , 1678-1712 (2015).

17. Sheltzer, J. M. \& Smith, J. C. Proc. Natl Acad. Sci. USA 111, 10107-10112 (2014).

18. Dutt, K., Pfaff, D. L., Bernstein, A. F., Dillard, J. S. \& Block, C. J. Nat. Geosci. 9, 805-808 (2016).

19. Schmader, T., Whitehead, J. \& Wysocki, V. H. Sex Roles 57, 509-514 (2007)

20. Shaw, A. K. \& Stanton, D. E. Proc. R. Soc. B 279, 3736-3741 (2012).

21. Lerchenmueller, M. J. \& Sorenson, O. Res. Policy 47, 1007-1017 (2018).

22. Van Dijk, D., Manor, O. \& Carey, L. B. Curr. Biol. 24, R516-R517 (2014).

23. Speakman, R. J. et al. PLoS ONE 13, e0202528 (2018).

24. Sege, R., Nykiel-Bub, L. \& Selk, S. JAMA 314, 1175-1177 (2015).

25. Kaminski, D. \& Geisler, C. Science 335, 864-866 (2012).

26. Jena, A. B., Khullar, D., Ho, O., Olenski, A. R. \& Blumenthal, D. M. JAMA 314, 1149-1158 (2015).

27. Thomas, N. R., Poole, D. J. \& Herbers, J. M. PLoS ONE 10, e0139767 (2015). 
28. Nittrouer, C. L. et al. Proc. Natl Acad. Sci. USA 115, 201708414 (2017).

29. Débarre, F., Rode, N. O. \& Ugelvig, L. V. Evol. Lett. 2, 148-158 (2018).

30. Isbell, L. A., Young, T. P. \& Harcourt, A. H. PLoS ONE 7, 2-5 (2012). 31. Lincoln, A. E., Pincus, S., Koster, J. B. \& Leboy, P. S. Soc. Stud. Sci. 42, 307-320 (2012).

32. Gibney, E. Nature 562, 19 (2018).

33. Carter, A. J., Croft, A., Lukas, D. \& Sandstrom, G. M. PLoS ONE 13, e0202743 (2018)
34. Loverock, B. \& Hart, M. M. Facets 3, 754-763 (2018). 35. MacNell, L., Driscoll, A. \& Hunt, A. N. Innov. High. Educ. 40, 291-303 (2015).

36. Massen, J. J. M., Bauer, L., Spurny, B., Bugnyar, T. \& Kret, M. E. Sci. Rep. 7, 12927 (2017).

37. Survey of Earned Doctorates 2016 (National Science Foundation, 2018).

38. Handley, I. M., Brown, E. R., Moss-Racusin, C. A. \& Smith, J. L. Proc. Natl Acad. Sci. USA 112, 13201-13206 (2015)
39. Leggon, C. B. Am. Behav. Sci. 62, 719-726 (2018).

40. Babcock, L., Recalde, M. P., Vesterlund, L. \& Weingart, L. Am. Econ. Rev. 107, 714-747 (2017)

41. Cameron, E. Z., White, A. M. \& Gray, M. E. Bioscience 66 245-252 (2016)

42. Guarino, C. M. \& Borden, V. M. H. Res. High. Educ. 58, 672-694 (2017).

Competing interests

The author declares no competing interests. 